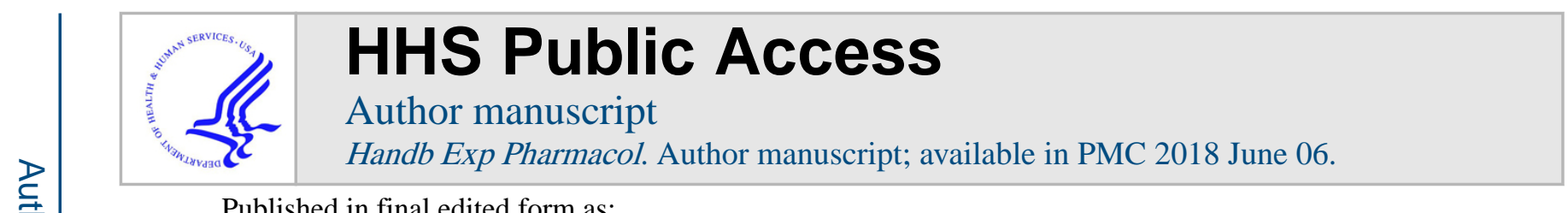

Published in final edited form as:

Handb Exp Pharmacol. 2018 ; 246: 309-330. doi:10.1007/164_2017_52.

\title{
Sodium Channelopathies of Skeletal Muscle
}

\author{
Stephen C. Cannon \\ Department of Physiology, David Geffen School of Medicine, Los Angeles, CA 90095, USA, \\ sccannon@mednet.ucla.edu
}

\section{XX.1 The $\mathrm{Na}^{+}$Channel of Skeletal Muscle}

The predominant sodium channel in skeletal muscle is a heterodimer of the pore-forming Nav1.4 a subunit (Trimmer et al., 1989) and the non-covalently associated $\beta_{1}$ subunit (Isom et al., 1992). A separate TTX-insensitive isoform, $\mathrm{Na}_{\mathrm{V}} 1.5$ which is the major a subunit in the heart (Gellens et al., 1992), conducts a minor component $(\sim 10 \%)$ of the total $\mathrm{Na}^{+}$current in adult skeletal muscle (Fu et al., 2011), but is the major isoform in fetal muscle and is upregulated in chronically denervated skeletal muscle (Rogart and Regan, 1985; Yang et al., 1991). The human $\mathrm{Na}_{\mathrm{V}} 1.4$ subunit is encoded by the $S C N 4 A$ gene on chromosome 17q23 (George et al., 1992), and the $\beta_{1}$ subunit by $S C N 1 B$ on chromosome 19q13.11 (McClatchey et al., 1993). Mutations of the $\beta_{1}$ subunit have been associated with epilepsy, ataxia, and cardiac arrhythmia (Calhoun and Isom, 2014), but have not been linked to a skeletal muscle phenotype.

The sodium channel complex is expressed in skeletal muscle plasma membranes of both the transverse tubules and the sarcolemma (DiFranco and Vergara, 2011; Jaimovich et al., 1976). Channels activate rapidly $(<1 \mathrm{msec})$ in response to depolarization and conduct a large inward $\mathrm{Na}^{+}$current $\left(\sim 5 \mathrm{~mA} / \mathrm{cm}^{2}\right)$ that drives the rapid upstroke of the action potential $(\mathrm{dV} / \mathrm{dt}$ $\sim 500 \mathrm{mV} / \mathrm{msec}$ ). The channel density is about 100-fold higher at the endplate of the neuromuscular junction (Caldwell et al., 1986), which contributes to the high safety factor of synaptic transmission such that a muscle fiber action potential is elicited for each motoneuron action potential that invades the nerve terminal.

The functional consequences of Nav1.4 mutations associated with muscle disorders have been studied primarily by heterologous expression in mammalian cell lines (HEK or tsA201 cells). Expression in Xenopus oocytes has also been used, but co-expression of the $\beta_{1}$ subunit is essential to suppress a gating mode with anomalously slow inactivation (Cannon et al., 1993b). A more limited number of studies have been performed on muscle biopsies (Lehmann-Horn et al., 1987), patient-derived cultured myotubes (Cannon et al., 1991), or knock-in mutant mouse models (Clausen et al., 2011). Fortunately, there has been good agreement in the conclusions drawn from this variety of experimental systems.

\section{XX.2 Clinical Phenotypes Associated with $\mathrm{Na}_{\mathrm{v}} 1.4$ Mutations}

Mutations of Nav1.4 produce a variety of skeletal muscle phenotypes (Cannon, 2015; Lehmann-Horn et al., 2004). Other excitable tissues, such as heart and brain, are not affected because the $\mathrm{Na}_{\mathrm{V}} 1.4$ isoform is expressed at significant levels only in skeletal muscle 
(Trimmer et al., 1989). Muscle excitability may be either pathologically enhanced or reduced as a consequence of $\mathrm{Na}_{\mathrm{V}} 1.4$ mutations.

Hyperexcitability presents clinically as muscle stiffness, termed myotonia, which results from an involuntary contraction that persists for several seconds after cessation of voluntary effort (Rüdel and Lehmann-Horn, 1985). This after-contraction is caused by a burst of muscle action potentials that lasts for several seconds, independent from any excitation from the motoneuron (Brown and Harvey, 1939). In patients with myotonia, the needle electromyogram shows sustained bursts of discharges that can be elicited by brief voluntary contraction or by direct mechanical percussion of the affected muscle. Symptomatically, the severity of myotonia fluctuates with the level of muscle activity. Myotonic stiffness is usually most pronounced with the first forceful movements after several minutes of rest, and then decreases over seconds to minutes with continued voluntary muscle activity (warm-up phenomenon). In some instances, myotonic stiffness may paradoxically worsen with repeated muscle effort and is termed paramyotonia. Myotonia may be aggravated by environmental trigger factors such as muscle cooling or ingestion of food with a high $\mathrm{K}^{+}$ content. Muscle hyperexcitability with myotonia occurs with either gain-of-function defects in mutant $\mathrm{Na}_{\mathrm{V}} 1.4$ subunits or loss-of-function mutations in the skeletal muscle chloride channel ClC-1 (Cannon, 2015).

Reduced excitability of skeletal muscle arising from $\mathrm{Na}_{\bigvee} 1.4$ defects may produce transient attacks of weakness or a chronic state of permanent myopathic weakness. The most common manifestation is periodic paralysis with recurrent episodes of moderate to severe weakness resulting from sustained depolarization of the resting potential that inactivates $\mathrm{Na}_{\mathrm{V}} 1.4$ and thereby reduces fiber excitability (Cannon, 2015; Lehmann-Horn et al., 2004). The attacks of weakness are often triggered by environmental factors such as rest after vigorous exercise, diet (fasting, carbohydrate ingestion, high salt) or emotional stress. A typical episode has a gradual onset over minutes, lasts for several hours to a day or more, followed by spontaneous recovery. The severity of an attack my render a patient bedridden, unable to sit or raise a limb against gravity. Many patients with periodic paralysis also develop a late onset permanent weakness that begins around age 40 years and is slowly progressive. Another $\mathrm{Na}_{\mathrm{V}}$ 1.4-associated phenotype, with a much lower prevalence, is myasthenia characterized by rapid fatigue of muscle strength within seconds to minutes (Tsujino et al., 2003). Recovery of strength also occurs quickly over minutes, and the muscles of the face, eyelids, tongue, neck, and soft palate are most commonly affected. In exemplary cases, clinical electrophysiologic testing shows a decremental response of the compound muscle action potential elicited by repetitive nerve stimulation. This decremental response is the hallmark of a compromised safety factor of neuromuscular transition, but in this case the defect is with the generation of a muscle action potential from a normal postsynaptic endplate potential. A third phenotype is congenital myopathy, with fetal or neonatal hypokinesia, reduced muscle tone, and moderate to severe fixed myopathic weakness (Zaharieva et al., 2015). 


\section{XX.3 Overview of $\mathrm{Na}_{v} 1.4$ Mutations}

The sodium channelopathies of skeletal muscle are rare diseases, with combined prevalence of about 1 per 100,000 (Horga et al., 2013). The inheritance pattern is autosomal dominant and highly penetrant, except for the very rare syndrome of congenital myopathy which is autosomal recessive. Over 70 mutations of $S C N 4 A$ have been identified in patients with skeletal muscle disorders (Huang et al., 2017; Lehmann-Horn and Jurkat-Rott, 1999). Genotype-phenotype associations have emerged (Miller et al., 2004; Rüdel et al., 1993), wherein specific mutations are consistently found to cause a particular clinical syndrome amongst the 6 allelic disorders of the muscle sodium channelopathies (Fig. XX.1). A major focus of functional expression studies over the past two decades has been to determine the repertoire of biophysical defects of channel behavior that predispose affected muscle to a particular phenotype. Most mutations are missense changes that alter channel function, with only a handful of nonsense, frameshift, or splice site mutations found in the recessive congenital myopathy families (Zaharieva et al., 2015). A small subset of missense mutations in Nav1.4 accounts for the majority of patients with myotonia or periodic paralysis (Horga et al., 2013; Matthews et al., 2008; Miller et al., 2004). Haplotype analysis of multiple families with the same missense mutation does not support the hypothesis of a common genetic ancestor (Wang et al., 1993), and the occurrence of de novo mutations has been verified in isolated probands.

Mammalian homologues $\mathrm{Na}_{\mathrm{V}} 1.4$ skeletal muscle channelopathies in non-human species occurred spontaneously in American quarter horses and have been genetically engineered in mice. The equine mutation has been traced to a founder animal with myotonia and periodic paralysis, and the selective breeding practices in the horse industry lead to rapid dissemination of the trait that now affects 5\% of all quarter horses (Rudolph et al., 1992). Three separate mouse lines with periodic paralysis or periodic paralysis plus myotonia have been generated by creating missense mutations of $\mathrm{Na}_{\mathrm{V}} 1.4$ by site-directed knock-in (Hayward et al., 2008; Wu et al., 2011) or ENU mutagenesis (Corrochano et al., 2014).

\section{XX.3.1 Gain of Function Mutations Cause Myotonia and Hyperkalemic Periodic Paralysis}

A subset of three muscle disorders with overlapping clinical symptoms have been associated with missense mutations that cause gain-of-function defects for Nav1.4 (Fig. XX.1) (Cannon, 2015; Lehmann-Horn et al., 2004). At one end of this spectrum, patients with sodium channel myotonia (SCM) have muscle stiffness and involuntary after-contractions without episodes of periodic paralysis. A diverse variety of clinical subtypes have been described, depending on the severity (e.g. myotonia permanens for severe dysfunction that may compromise breathing (Singh et al., 2014)) or on precipitating factors (e.g. potassiumaggravated myotonia (Heine et al., 1993)). Myotonia that paradoxically worsens with repeated muscle activity or with muscle cooling is the hallmark of paramyotonia congenita (PMC), but patients may also have episodes of periodic paralysis. In hyperkalemic periodic paralysis (HyperPP) recurrent attacks of periodic paralysis, often in association with elevated serum $[\mathrm{K}+]>5 \mathrm{mM}$ or precipitated by a $\mathrm{K}^{+}$challenge, are the predominant symptom. Patients with HyperPP frequently have myotonia, especially around the time of an episode of weakness. The clinical overlap of PMC and HyperPP is extensive, and family 
members with the same Nav1.4 mutation may have a syndrome typical of PMC or HyperPP (Brancati et al., 2003; Kelly et al., 1997; McClatchey et al., 1992).

XX.3.1.1 Gating Defects in Myotonia and HyperPP_Expression studies of $\mathrm{Na}_{\mathrm{V}} 1.4$ mutant channels associated with SCM, PMC, and HyperPP have revealed a variety of gating defects, all of which result in gain-of-function changes that increase $\mathrm{Na}^{+}$influx. Most often, these changes disrupt inactivation gating of mutant channels (Fig. XX.2), and in some cases there is enhancement of activation. The inactivation defects include: (a) an increased persistent current that fails to inactivate over hundreds of msec (Cannon et al., 1991; Cannon and Strittmatter, 1993), (b) slower rate for entry to inactivation (Lerche et al., 1993; Yang et al., 1994), (c) faster rate of recovery from inactivation, and (Green et al., 1998)(d) a depolarized shift in the voltage-dependence of steady-state inactivation (Hayward et al., 1996; Mitrovic et al., 1995). These defects all disrupt conventional "fast" inactivation of $\mathrm{Na}_{\mathrm{V}} 1.4$, which occurs over a time course of msec and is important for shaping the repolarizing phase of the action potential and for limiting the propensity for repetitive firing during the refractory interval. The primary effect on fast inactivation gating is consistent with structure-function models of $\mathrm{Na}_{\mathrm{V}}$ channels. The SCM/PMC/HyperPP mutations are clustered in the domain III-IV loop (the inactivation gate) (Stühmer et al., 1989; West et al., 1992), the cytoplasmic end of S5 and S6 segments at the inner mouth of the pore (the docking site for the inactivation gate), and the voltage sensor of domain IV (voltage sensor most tightly coupled to fast inactivation) (Capes et al., 2013).

All eukaryotic $\mathrm{NaV}$ channels also undergo slow inactivation, as revealed by a slow time course of recovery on the order of seconds. Channels become slow inactivated during prolonged intervals of depolarization lasting tens of seconds to minutes or during sustained high-frequency bursts of action potentials (Simoncini and Stuhmer, 1987). Slow inactivation gating mechanisms are structurally distinct from those domains involved with fast inactivation. For example, mutations of the cytoplasmic III-IV loop may abolish fast inactivation but do not disrupt slow inactivation (Cummins and Sigworth, 1996;

Featherstone et al., 1996). Slow inactivation is impaired for several mutations associated with PMC/HyperPP, but not for SCM mutant channels (Hayward et al., 1997). The slow inactivation defects are manifest as a depolarized shift in voltage-dependence, an increased fraction of channels that do not slow inactivate, or a faster rate of recovery.

Activation gating may also be altered to produce gain-of-function changes in $\mathrm{Na}_{\mathrm{V}} 1.4$ mutations associated with muscle channelopathies. The anomalous enhancement of activation for mutant channels occurs by a hyperpolarized shift in voltage-dependence (Cummins et al., 1993) or a slower rate of deactivation (Featherstone et al., 1998).

XX.3.1.2 Pathophysiologic Mechanism of Myotonia and HyperPP-Mutations of $\mathrm{Na}_{V} 1.4$ that produce gain-of-function defects with excessive inward $\mathrm{Na}^{+}$current at the channel level, may cause either enhanced excitability (myotonia) or a transient loss of excitability (periodic paralysis) at the cellular level. Experimental evidence that a gain of function defect for $\mathrm{Na}_{\mathrm{V}} 1.4$ is sufficient to cause these divergent effects on muscle excitability has been obtained for toxin-based models that disrupt $\mathrm{Na}_{\mathrm{V}} 1.4$ inactivation (Cannon and Corey, 1993) and for knock-in mutant mouse models (Corrochano et al., 2014; 
Hayward et al., 2008). The knock-in mouse homolog of M1592V has a robust HyperPP phenotype with myotonia by EMG, hindlimb stiffness, and reduced tetanic force in the setting of a $10 \mathrm{mM} \mathrm{K}^{+}$challenge in vitro (Hayward et al., 2008). Complementary studies using computer simulation of muscle excitability provide additional insights on pathomechanism by providing a mechanism to define the type and magnitude of gating defect that is necessary to cause myotonia or periodic paralysis (Cannon et al., 1993a). The model correlate of myotonia is sustained bursts of action potentials, whereas periodic paralysis is manifest as an anomalous stable depolarization of $\mathrm{V}_{\text {rest }}$ that inactivates the simulated $\mathrm{Na}^{+}$conductance and renders the model fiber inexcitable.

Simulations have demonstrated that some gain-of-function defects predispose to myotonia while others increase the susceptibility to periodic paralysis. For example, Nav1.4 mutations found in SCM patients, who by definition have myotonia but no periodic paralysis, alter the kinetics of channel inactivation with a slower rate on onset and sometimes with faster recovery as well (Green et al., 1998; Yang et al., 1994). These changes increase the fraction of sodium channels that remain available for activation (i.e. non-inactivated) immediately after an action potential, which in turn increases the likelihood of repetitive after-discharges (Fig. XX.3, middle). Because the gain-of-function defect is transient, without a persistent $\mathrm{Na}$ + current in steady-state, the simulation will never produce the stable depolarization of $\mathrm{V}_{\text {rest }}$ required to produce periodic paralysis. The myotonic burst is sustained by the modest afterdepolarization arising from use-dependent $\mathrm{K}^{+}$accumulation in the T-tubules, an extracellular space with restricted diffusion. Normally, $\mathrm{Na}_{\mathrm{V}} 1.4$ channel availability is too low immediately after an action potential for this transient after-depolarization to trigger another spike, but for SCM mutant channels the increased availability may elicit an after-discharge. Experimental support for this mechanism has been obtained in animal models of myotonia, where muscle fiber detubulation abolishes the transient after-depolarization and the burst of myotonic discharges (Cannon and Corey, 1993).

In contrast, the gain-of-function defects for $\mathrm{Na}_{\mathrm{V}} 1.4$ mutant channels associated with HyperPP often include an anomalous persistent $\mathrm{Na}^{+}$current from incomplete inactivation or a shift in the steady-state voltage dependence of gating (Cannon and Strittmatter, 1993; Hayward et al., 1996). Voltage-clamp studies of wild type Nav1.4 show fast inactivation of $\mathrm{Na}^{+}$currents within a msec and a barely perceptible fraction of non-inactivating current that is about $0.2 \%$ of the transient peak amplitude. For HyperPP mutant channels, however, the persistent current is $1 \%$ to $4 \%$ of the transient peak (Cannon et al., 1991). While the absolute magnitude of this persistent current is small, the 5- to 20-fold relative increase has a large effect on simulated fiber excitability. Quiescent fibers have a normal $\mathrm{V}_{\text {rest }}$, where $\mathrm{Na}_{\mathrm{V}} 1.4$ channels are closed and the gain-of-function defect is silent. Brief stimulation may elicit a burst of myotonic discharges, and as $\mathrm{K}^{+}$accumulates in the T-tubules the moderate afterdepolarization in conjunction with a persistent defect of $\mathrm{Na}_{\mathrm{V}} 1.4$ inactivation results in a steady inward $\mathrm{Na}^{+}$current that keeps the fiber stably depolarized at about $-45 \mathrm{mV}$ (Fig XX. 3 , right). From this anomalously depolarized $\mathrm{V}_{\text {rest }}$ the wild type $\mathrm{Na}_{\mathrm{V}} 1.4$ channels and most of the HyperPP mutant channels are inactivated, which renders the fiber chronically refractory and unable to generate an action potential. The mutant allele has a dominantnegative effect on fiber excitability, acting through voltage-dependent inactivation. This scenario also explains why exogenous administration of $\mathrm{K}^{+}$may elicit an attack of weakness 
in HyperPP. Model simulations show a similar mechanism occurs for HyperPP gain-offunction mutations that enhance activation from a left shift in voltage dependence. The increased overlap of steady-state inactivation and activation creates a persistent "window" current in the voltage range of $-65 \mathrm{mV}$ to $-45 \mathrm{mV}$.

Slow inactivation of $\mathrm{Na}_{\mathrm{V}} 1.4$ channels will attenuate the persistent current from a fast inactivation defect and thereby is predicted to reduce the susceptibility to periodic paralysis (Ruff, 1994). Voltage-clamp studies revealed impairment of slow inactivation for the two most commonly occurring mutations in HyperPP (T704M and M1592V) and for a subset of other mutations in HyperPP and PMC (Cummins and Sigworth, 1996; Hayward et al., 1997). About $90 \%$ of wild type $\mathrm{Na}_{V} 1.4$ channels will slow inactivate at depolarized potentials, whereas the mutant channels have a combination of defects with larger noninactivating fraction $(20 \%-40 \%)$, a right shift in voltage dependence, or a faster rate of recovery. Not all PMC/HyperPP mutant channels tested had a detectable impairment of slow inactivation, but every $\mathrm{Na}_{\mathrm{V}} 1.4$ mutation with a defect of slow inactivation was associated with a phenotype where periodic paralysis was a prominent symptom (Hayward et al., 1999). The interpretation is that impaired slow inactivation markedly increases the risk of depolarization-induced attacks of periodic paralysis, but that because normal slow inactivation is only about $70 \%$ to $80 \%$ complete at $-50 \mathrm{mV}$ then a severe defect of fast inactivation alone is sufficient to produce stable depolarization with paralysis.

\section{XX.3.2 Anomalous Gating Pore Conduction in Hypokalemic Periodic Paralysis}

Hypokalemic periodic paralysis presents with recurrent episodes of weakness in association with low serum $\mathrm{K}^{+}(<3.0 \mathrm{mM})$. Attacks of weakness in HypoPP are often precipitated by events that promote a reduction of extracellular $\mathrm{K}^{+}$such as a concentrated oral load of carbohydrate (which shifts glucose and $\mathrm{K}^{+}$into muscle), or $\mathrm{K}^{+}$loss from vomiting or diarrhea (Cannon, 2015; Lehmann-Horn et al., 2004). Myotonia does not occur in HypoPP, and is an exclusion criterion for the diagnosis. The genetic lesion in HypoPP is heterogeneous, with $60 \%$ of families having a missense mutation in the skeletal muscle calcium channel ( $\mathrm{Ca}_{\mathrm{V}} 1.1$ encoded by $\left.C A C N A 1 S\right)$ and $20 \%$ with a missense mutation of $S C N 4 A$ encoding Nav1.4 (Sternberg et al., 2001). Remarkably, all 12 HypoPP mutations in $\mathrm{Na}_{V} 1.4$ and 8 of 9 mutations in $\mathrm{Ca}_{\mathrm{V}} 1.1$ are missense substitutions at arginine residues in S4 segments of the voltage sensor domains (VSD) (Matthews et al., 2009). This convergence of mutation sites at homologous positions in the VSDs of $\mathrm{Ca}_{\mathrm{V}} 1.1$ and $\mathrm{Na}_{\mathrm{V}} 1.4$ has led to the notion that a common pathomechanism underlies the susceptibility to intermittent depolarization with paralysis (Cannon, 2010). This hypothesis is consistent with the clinical experience that the signs and symptoms of HypoPP are indistinguishable for patients with Cav1.1 or Nav1.4 mutations.

XX.3.2.1 Gating Pore Current in HypoPP Mutant Channels-Functional expression studies of Nav1.4 HypoPP mutant channels initially focused on voltage-dependent gating of the $\mathrm{Na}^{+}$conductance, since the mutations all occurred in VSDs. Moderate loss-of-function changes were identified, with enhanced slow inactivation (left shift and slower rate of recovery (Struyk et al., 2000)) or a left shift of fast inactivation with reduced current density (Jurkat-Rott et al., 2000). In addition, substantial decoupling of gating charge displacement 
to channel opening further contributes to a reduced peak $\mathrm{Na}^{+}$current in HypoPP mutant channels (Mi et al., 2014). These changes suggested a dichotomy to account for divergent clinical phenotypes from Nav1.4 mutations - gain-of-function defects predispose to myotonia and HyperPP, whereas loss-of-function defects cause HypoPP - but there was no satisfactory explanation for how loss-of-function for $\mathrm{Na}_{\mathrm{V}} 1.4$ would cause paradoxical depolarization and loss of excitability in low extracellular $\mathrm{K}^{+}$.

Histidine scanning mutagenesis to ascertain voltage-dependent conformational changes in the S4 segments of Shaker $\mathrm{K}_{\mathrm{V}}$ channels revealed a secondary pathway for translocation of protons across the membrane, either by a transporter mechanism (Starace et al., 1997) or conduction through an aqueous path (Starace and Bezanilla, 2001; Starace and Bezanilla, 2004). Substitution of the first arginine in S4 by smaller hydrophobic residues created a nonselective monovalent cation conductance, the so-called omega-current or gating pore current, as distinguished from the conventional "alpha" current through the canonical pore domain (Tombola et al., 2005). Homologous mutations at a pair of arginines in DIIS4 of Nav1.2 also resulted in a gating pore current (Sokolov et al., 2005). This observation raised the possibility that all members of the voltage-gated ion channel superfamily might support a gating pore current when S4 in the VSD is mutated (Moreau et al., 2014), including by disease-associated mutations. The mechanistic interpretation was that voltage-dependent translocation of the S4 helix occurs through an aqueous crevice in the channel (Starace and Bezanilla, 2004) that has a hydrophobic narrow waist - the gating charge transfer center (GCTC) - that normally impedes ion conduction (Tao et al., 2010; Wood et al., 2017). Mutation of an arginine in S4 may allow ion conduction through the gating pore, when the mutant residue is aligned with the GCTC. This scenario is consistent with the voltagedependence of the permissive state for ion conduction that has been observed for gating pore currents (Sokolov et al., 2005; Starace and Bezanilla, 2004).

The HypoPP associated mutations of $\mathrm{Na}_{\mathrm{V}} 1.4$ are in the outer arginines at the amino end of S4 segments (Matthews et al., 2009), and so a gating pore current would be expected to show inward rectification, with ion conduction occurring at hyperpolarized potentials that bias S4 in the "downward" closed channel conformation. When HypoPP Nav1.4 mutant channels are expressed at very high levels in Xenopus oocytes, a TTX-insensitive inward rectifying current is detectable, consistent with a gating pore current (Fig. XX.4), and which is not seen for wild type Nav1.4 channels (Sokolov et al., 2007; Struyk and Cannon, 2007; Struyk et al., 2008). The two HypoPP mutations in DIIS4 that are arginine to histidine substitutions (R669H and $\mathrm{R} 672 \mathrm{H}$ ) both conduct proton-selective gating pore currents (Struyk and Cannon, 2007; Struyk et al., 2008). Interestingly, the clinical phenotype is no different for proton selective versus cation non-selective HypoPP mutations. Eight out of the 12 reported HypoPP mutations in Nav1.4 have been screened, and all 8 had detectable gating pore currents. Moreover, the PMC associated mutation in DIVS4 (R1448C at the R1 position) did not have a detectable gating pore current (Francis et al., 2011), thereby showing specificity with gating pore currents observed only in HypoPP mutant channels. Histidine screening mutagenesis in S4 segments for all four domains of Nav1.4 shows that the DIV VSD is more resistant to the creation of a gating pore leak, possibly because the GCTC is spread over a larger distance (Gosselin-Badaroudine et al., 2012). An inward rectifying current, consistent with a gating pore current, has also been detected in muscle 
fibers from R669H HypoPP mice, which verifies this anomalous current occurs in the context of mammalian skeletal muscle (Wu et al., 2011).

XX.3.2.2 Pathophysiologic Mechanism for HypoPP—A confluence of experimental evidence and computer modeling supports the hypothesis that the gating pore current is the critical anomaly for HypoPP mutant channels in causing susceptibility to paradoxical depolarization and weakness in low $\mathrm{K}^{+}$. Investigations with human HypoPP muscle biopsies implicated an unusual source for the depolarizing current, since TTX did not prevent depolarization of Nav1.4 HypoPP fibers (Jurkat-Rott et al., 2000) nor did calcium channel blockers for Cav1.1 associated HypoPP (Ruff, 1999). All 12 HypoPP mutations in Nav1.4 are missense mutations at arginines in the outer ends of S4 segments in the VSD, and all 8 tested to date had detectable gating pore currents. Moreover, the $\mathrm{Ca}_{\mathrm{V}} 1.1$ mutations in HypoPP are also R/X substitutions in S4 segments of the VSD, and voltage-clamp studies of Cav1.1-R528H human fibers (Jurkat-Rott et al., 2009; Ruff, 1999) and knock-in mice (Wu et al., 2012) also revealed an inward rectifying gating pore current.

The mechanism by which the gating pore current produces susceptibility to depolarization and weakness in low $\mathrm{K}^{+}$has been tested and supported by computer simulation (Jurkat-Rott et al., 2010; Struyk and Cannon, 2008). In quantitative terms, gating pore currents are very small, with the conductance being about $0.03 \%$ the peak $\mathrm{Na}^{+}$conductance through the conventional pore (Mi et al., 2014). In skeletal muscle at $\mathrm{V}_{\text {rest }}$, the gating pore conductance is about $10 \mu \mathrm{S} / \mathrm{cm}^{2}$ or $1 \%$ of the total resting conductance of the fiber. The gating pore current will promote depolarization, since the reversal potential is near $0 \mathrm{mV}$, regardless of whether the conductance is proton selective or non-selective for monovalent cations. Based on these values, the impact of the anomalous gating pore current on a simulated resting fiber is modest in normal external $\mathrm{K}^{+}(4.5 \mathrm{mM})$, with a predicted depolarization of about $3 \mathrm{mV}$. In low extracellular $\mathrm{K}^{+}$, however, the impact can be large. As $\mathrm{K}^{+}$is reduced, the equilibrium or Nernst potential for $\mathrm{K}^{+}$becomes more negative, and initially the simulated fiber hyperpolarizes. In low $\mathrm{K}^{+}$, the membrane voltage at which strong rectification occurs for the inward rectifier K channel (Kir) also becomes more negative. This shift of the rectification point for Kir will eventually reduce the outward $\mathrm{K}^{+}$current available to balance inward currents from ClC- 1 chloride channels and the gating pore. (Recall in steady-state $\mathrm{V}_{\text {rest }}$ is always more positive than $\mathrm{E}_{\mathrm{K}}$ so the current will be outward through $\mathrm{Kir}$ ). When $\mathrm{K}^{+}$is further reduced and the Kir current becomes too small to balance the $\mathrm{ClC}-1$ and gating pore inward current, the fiber will depolarize until the delayed rectifier $\mathrm{K}$ channel (Kdr) opens and again establishes a net balance of 0 ionic current. In essence, the $\mathrm{K}^{+}$channel that dominates for setting $\mathrm{V}_{\text {rest }}$ switches from Kir (normally polarized $\mathrm{V}_{\text {rest }}$ ) to $\mathrm{Kdr}$ (abnormally depolarized). At this anomalously depolarized $\mathrm{V}_{\text {rest }}, \mathrm{Na}_{\mathrm{V}} 1.4$ channels are inactivated, the fiber is inexcitable, and flaccid weakness ensues. Of course, this same mechanism applies to wild-type fibers, as has been demonstrated experimentally in mammalian fibers (Siegenbeek van Heukelom, 1991), but in the absence of a gating pore current the critical $\left[\mathrm{K}^{+}\right]$for paradoxical depolarization is about $1 \mathrm{mM}$, far below the normal physiologic range. The anomalous gating pore current conducted by HypoPP mutant channels shifts the critical $\mathrm{K}^{+}$ value up to about $3.0-3.5 \mathrm{mM}$, at the low end of the normal physiologic range. In addition, the loss-of-function changes in HypoPP mutant $\mathrm{Na}_{\mathrm{V}} 1.4$ channels (enhanced inactivation and 
partial decoupling of charge movement to channel opening) will further contribute to the reduced excitability caused by depolarization of $\mathrm{V}_{\text {rest }}$. The response of $\mathrm{V}_{\text {rest }}$ to changes in extracellular $\mathrm{K}^{+}$is summarized in the phase plot for simulated wild-type and HypoPP fibers in Fig. XX.5.

The chloride gradient across the sarcolemma has a strong influence over the susceptibility to depolarization and periodic paralysis for HypoPP fibers in low $\mathrm{K}^{+}$. This modulation by $\mathrm{Cl}^{-}$ occurs because $\mathrm{ClC}-1$ channels contribute about $85 \%$ of the total resting conductance in skeletal muscle (Palade and Barchi, 1977). The reversal potential for $\mathrm{Cl}$ is about $3 \mathrm{mV}$ depolarized from $\mathrm{V}_{\text {rest }}$ because influx via the $\mathrm{Na}^{+}-\mathrm{K}^{+}-2 \mathrm{Cl}^{-}$cotransporter (NKCC) maintains the intracellular $\mathrm{Cl}^{-}$slightly higher than the equilibrium value predicted for a passive electrochemical distribution (Aickin et al., 1989). Consequently, a steady inward $\mathrm{Cl}^{-}$current (efflux of the $\mathrm{Cl}^{-}$anion) through $\mathrm{ClC}-1$ channels is the primary depolarizing current that is balanced at rest by the outward hyperpolarizing $\mathrm{K}^{+}$current conducted by Kir channels. Recordings from mammalian fibers and computer simulations (Gallaher et al., 2009) show that this combination of resting conductances gives rise to the possibility of two resting potentials (net ionic current is 0 for both cases) over a range of low external $\mathrm{K}^{+}$values (Fig. XX.5). The bistability of two resting potentials in skeletal muscle is not the result of an " $\mathrm{N}$ "shaped steady-state I-V relation, with three critical membrane potentials at which the total current is 0 (e.g. the classical cardiac Purkinje cell model (Gadsby and Cranefield, 1977)). The large resting $\mathrm{Cl}^{-}$conductance prevents such a scenario. Instead, a shift in the intracellular $\left[\mathrm{Cl}^{-}\right]$is the critical state variable that determines whether $\mathrm{V}_{\text {rest }}$ will lie on the hyperpolarized branch (low internal $\mathrm{Cl}^{-}$, preserved excitability) or the depolarized branch (high internal $\mathrm{Cl}^{-}$, loss of excitability). This insight led to the suggestion that maneuvers to manipulate the sarcolemma $\mathrm{Cl}^{-}$gradient should have a strong modulating effect on the susceptibility to attacks of weakness in HypoPP (Geukes Foppen et al., 2002). Indeed, inhibition of the NKCC cotransporter with bumetanide, which will reduce intracellular [Cl -], completely prevents the loss of force from a $2 \mathrm{mM} \mathrm{K}^{+}$challenge in the Nav1.4-R669H mouse model of HypoPP (Wu et al., 2013). Conversely, a hyperosmolar challenge, which stimulates NKCC and increases intracellular $\left[\mathrm{Cl}^{-}\right]$, may trigger a loss of force or aggravate the response to a low $\mathrm{K}^{+}$challenge.

\section{XX.3.3 Loss of Function Mutations: Myasthenia and Congenital Myopathy}

In myasthenia, voluntary muscle force rapidly fatigues, because of a loss in the safety factor of neuromuscular transmission. The synaptic defect is usually postsynaptic, as in myasthenia gravis with antibody-mediated loss of the nicotinic acetylcholine receptor and defacement of the endplate zone, or may be presynaptic as with congenital myasthenic syndromes (CMS) caused by genetic defects in acetylcholine synthesis or packaging into vesicles (Engel et al., 2003). A sodium channel based myasthenic syndrome was initially identified in a patient with fatigable weakness and the typical decremental response of the compound muscle action potential with repetitive nerve stimulation, but surprisingly the postsynaptic endplate potential was of normal amplitude (Tsujino et al., 2003). This combination of effects suggested a defect in muscle excitability downstream from the neuromuscular junction, and sequencing of $S C N 4 A$ revealed a missense mutation in the voltage sensor of domain IV. Increased awareness that mutations of $\mathrm{Na}_{\mathrm{V}} 1.4$ may occur in patients with symptomatic 
overlap between myasthenia and periodic paralysis led to the identification of additional isolated CMS cases, each of which was associated with recessive inheritance and homozygous missense mutations at arginines in the S4 of domain IV (Arnold et al., 2015; Habbout et al., 2016).

The congenital myopathies are a clinically and genetically diverse group of disorders with neonatal or early-onset weakness and characteristic changes on muscle biopsy. Over 20 different causative genes have been identified and the phenotype may vary from reduced fetal movements with neonatal fatality or mild disability with a normal lifespan. Whole exome sequencing from a large international consortium of congenital myopathy cases revealed 11 individuals with $S C N 4 A$ mutations from 6 families (Zaharieva et al., 2015). The clinical features ranged from fetal loss or death within the first two days ( 7 cases) to reduced muscle tone at birth and moderately severe myopathy but retained ability for independent ambulation. The severe cases were all homozygous null mutations for $\mathrm{Na}_{\mathrm{V}} 1.4$ whereas the less severe phenotypes had homozygous loss-of-function mutations or compound heterozygous mutations with a null allele and a loss-of-function mutation on the trans allele. Congenital myopathy patients who survived beyond childhood also had muscle fatigue and episodes of weakness, suggesting a partial overlap with myasthenia and periodic paralysis. All 12 parents were genetically confirmed to be heterozygous carriers, and all were asymptomatic with a normal neurological exam, thereby showing for the first time that a single null allele for $S C N 4 A$ is well tolerated without a detectable clinical deficit.

XX.3.3.1 Loss of Function Defects in Myasthenia and Myopathy-Expression studies of Nav1.4 missense mutations associated with CMS or congenital myopathy show loss-of-function defects. The CMS mutations cause a pronounced leftward shift ( -15 to -20 $\mathrm{mV}$ ) for the voltage dependence of fast inactivation (Arnold et al., 2015; Tsujino et al., 2003), slower recovery from inactivation, and for R1454W a markedly faster onset of slow inactivation (> 2 orders of magnitude) (Habbout et al., 2016). This combination of defects greatly enhances the use-dependent reduction of peak $\mathrm{Na}^{+}$current during a high frequency train $(50 \mathrm{~Hz})$ of brief depolarizations. The Nav1.4 missense mutations found in congenital myopathy either did not produced detectable $\mathrm{Na}^{+}$current ( 3 of 7 ), had substantially reduced $\mathrm{Na}^{+}$current density ( 3 of 4 expressing), or a depolarized shift of activation ( 2 of 4 expressing) (Zaharieva et al., 2015). Curiously, one missense mutation with an associated frameshift truncation (H1782Qfs65) was indistinguishable from wild-type in the HEK cell expression system. Otherwise, the congenital myopathy NaV1.4 mutations consistently displayed loss-of-function defects.

XX.3.3.2 Pathophysiologic Mechanism of Myasthenic Weakness-The loss-offunction defects identified for Nav1.4 in myasthenia will reduce the available pool of channels at the resting potential of $-90 \mathrm{mV}$ (large left shift of fast inactivation) and greatly accentuate the use-dependent reduction of peak $\mathrm{Na}^{+}$current during high-frequency discharges (slower recovery from inactivation, faster entry to slow inactivation). The mode of inheritance for the Nav1.4 myasthenic syndrome is autosomal recessive (Arnold et al., 2015; Habbout et al., 2016), suggesting that a large use-dependent reduction of $\mathrm{Na}^{+}$current (an acute change) is required to cause intermittent failure of spike generation from the 
endplate depolarization at the NMJ or to reduce the action potential amplitude, and thereby cause fatigable weakness. The heterozygous parental carriers with one copy of the CMS mutation are asymptomatic, so a mild use-dependent loss of $\mathrm{Na}^{+}$current must be well tolerated. Chronically, even a complete null for one allele does not cause symptoms, as was detected in the parents of the congenital myopathy patients (Zaharieva et al., 2015).

An $\mathrm{Na}_{\mathrm{V}} 1.4$ knock-out mouse model also supports the notion that an acute reduction for a substantial portion of the $\mathrm{Na}^{+}$current is required to produce myasthenia (Wu et al., 2016). Mice heterozygous for a deletion of exon 12 have a $50 \%$ reduction of $\mathrm{Na}^{+}$current density in muscle, but no obvious motor phenotype. So mice, like humans, tolerate a null allele for $S C N 4 A$ without an appreciable deficit in behavior. Expression of the embryonic isoform, $\mathrm{Na}_{\mathrm{V}} 1.5$, was not upregulated in adult mice to compensate for the reduced current density. Homozygous knock-out mice do not survive beyond the second postnatal day. In vitro contraction testing revealed a latent myasthenic phenotype in the heterozygous exon 2 deleted mice, with a sag in the muscle force plateau during tetanic stimulation and a decremental response of the compound muscle action potential during repetitive nerve stimulation in low-dose curare.

Taken together, the data for recessively inherited myasthenia or congenital myopathy imply a gene-dosage effect, and also a dependence on whether the mutant allele is a partial loss-offunction (hypomorphic) or a complete null. Fig. XX.6 illustrates these interactions amongst the different alleles. The vertices of the triangle represent the three possible homozygous states (WT/WT, LOF/LOF, null/null), and the midpoints on the sides of the triangle represent all possible combinations of heterozygotes (WT/LOF, WT/null, LOF/null). The large yellow shaded area shows that three possible combinations will be asymptomatic (WT/WT, WT/LOF, WT/null). When both alleles are mutant, there is a spectrum of clinical phenotype severity ranging from the mildest being myasthenia (LOF/LOF), to congential myopathy with survival to adulthood (LOF/null), and then the neonatal lethal incompatible with survival (null/null).

\section{References}

Aickin CC, Betz WJ, Harris GL. Intracellular chloride and the mechanism for its accumulation in rat lumbrical muscle. J Physiol. 1989; 411:437-455. [PubMed: 2515275]

Arnold WD, Feldman DH, Ramirez S, He L, Kassar D, Quick A, Klassen TL, Lara M, Nguyen J, Kissel JT, Lossin C, Maselli RA. Defective fast inactivation recovery of Nav 1.4 in congenital myasthenic syndrome. Ann Neurol. 2015; 77:840-850. [PubMed: 25707578]

Brancati F, Valente EM, Davies NP, Sarkozy A, Sweeney MG, LoMonaco M, Pizzuti A, Hanna MG, Dallapiccola B. Severe infantile hyperkalaemic periodic paralysis and paramyotonia congenita: broadening the clinical spectrum associated with the T704M mutation in SCN4A. J Neurol Neurosurg Psychiatry. 2003; 74:1339-1341. [PubMed: 12933953]

Brown GL, Harvey AM. Congenital myotonia in the goat. Brain. 1939; 62:341-363.

Caldwell JH, Campbell DT, Beam KG. Na channel distribution in vertebrate skeletal muscle. J Gen Physiol. 1986; 87:907-932. [PubMed: 2425042]

Calhoun JD, Isom LL. The role of non-pore-forming beta subunits in physiology and pathophysiology of voltage-gated sodium channels. Handb Exp Pharmacol. 2014; 221:51-89. [PubMed: 24737232]

Cannon SC. Voltage-sensor mutations in channelopathies of skeletal muscle. J Physiol. 2010; 588:1887-1895. [PubMed: 20156847] 
Cannon SC. Channelopathies of skeletal muscle excitability. Comprehensive Physiology. 2015; 5:761790. [PubMed: 25880512]

Cannon SC. When all is lost...a severe myopathy with hypotonia from sodium channel mutations. Brain. 2016; 139:642-644. [PubMed: 26917582]

Cannon SC, Brown RH Jr, Corey DP. A sodium channel defect in hyperkalemic periodic paralysis: potassium-induced failure of inactivation. Neuron. 1991; 6:619-626. [PubMed: 1849724]

Cannon SC, Brown RH Jr, Corey DP. Theoretical reconstruction of myotonia and paralysis caused by incomplete inactivation of sodium channels. Biophys. J. 1993a; 65:270-288. [PubMed: 8396455]

Cannon SC, Corey DP. Loss of Na+ channel inactivation by anemone toxin (ATX II) mimics the myotonic state in hyperkalaemic periodic paralysis. J. Physiol. 1993; 466:501-520. [PubMed: 8105077]

Cannon SC, McClatchey AI, Gusella JF. Modification of the $\mathrm{Na}^{+}$current conducted by the rat skeletal muscle alpha subunit by coexpression with a human brain beta subunit. Pflugers Archiv. 1993b; 423:155-157. [PubMed: 7683789]

Cannon SC, Strittmatter SM. Functional expression of sodium channel mutations identified in families with periodic paralysis. Neuron. 1993; 10:317-326. [PubMed: 8382500]

Capes DL, Goldschen-Ohm MP, Arcisio-Miranda M, Bezanilla F, Chanda B. Domain IV voltagesensor movement is both sufficient and rate limiting for fast inactivation in sodium channels. J Gen Physiol. 2013; 142:101-112. [PubMed: 23858005]

Clausen T, Nielsen OB, Clausen JD, Pedersen TH, Hayward LJ. Na+,K+-pump stimulation improves contractility in isolated muscles of mice with hyperkalemic periodic paralysis. J Gen Physiol. 2011; 138:117-130. [PubMed: 21708955]

Corrochano S, Mannikko R, Joyce PI, McGoldrick P, Wettstein J, Lassi G, Raja Rayan DL, Blanco G, Quinn C, Liavas A, Lionikas A, Amior N, Dick J, Healy EG, Stewart M, Carter S, Hutchinson M, Bentley L, Fratta P, Cortese A, Cox R, Brown SD, Tucci V, Wackerhage H, Amato AA, Greensmith L, Koltzenburg M, Hanna MG, Acevedo-Arozena A. Novel mutations in human and mouse SCN4A implicate AMPK in myotonia and periodic paralysis. Brain. 2014; 137:3171-3185. [PubMed: 25348630]

Cummins TR, Sigworth FJ. Impaired slow inactivation in mutant sodium channels. Biophys. J. 1996; 71:227-236. [PubMed: 8804606]

Cummins TR, Zhou J, Sigworth FJ, Ukomadu C, Stephan M, Ptacek LJ, Agnew WS. Functional consequences of a $\mathrm{Na}+$ channel mutation causing hyperkalemic periodic paralysis. Neuron. 1993; 10:667-678. [PubMed: 8386527]

DiFranco M, Vergara JL. The Na conductance in the sarcolemma and the transverse tubular system membranes of mammalian skeletal muscle fibers. J Gen Physiol. 2011; 138:393-419. [PubMed: 21948948]

Engel AG, Ohno K, Sine SM. Neurological diseases: Sleuthing molecular targets for neurological diseases at the neuromuscular junction. Nat Rev Neurosci. 2003; 4:339-352. [PubMed: 12728262]

Featherstone DE, Fujimoto E, Ruben PC. A defect in skeletal muscle sodium channel deactivation exacerbates hyperexcitability in human paramyotonia congenita. J Physiol. 1998; 506(Pt 3):627638. [PubMed: 9503326]

Featherstone DE, Richmond JE, Ruben PC. Interaction between fast and slow inactivation in SkM1 sodium channels. Biophys. J. 1996; 71:3098-3109. [PubMed: 8968581]

Francis DG, Rybalchenko V, Struyk A, Cannon SC. Leaky sodium channels from voltage sensor mutations in periodic paralysis, but not paramyotonia. Neurology. 2011; 76:1635-1641. [PubMed: 21490317]

Fu Y, Struyk A, Markin V, Cannon S. Gating behaviour of sodium currents in adult mouse muscle recorded with an improved two-electrode voltage clamp. J Physiol. 2011; 589:525-546. [PubMed: 21135045]

Gadsby DC, Cranefield PF. Two levels of resting potential in cardiac Purkinje fibers. J Gen Physiol. 1977; 70:725-746. [PubMed: 591921]

Gallaher J, Bier M, Siegenbeek van Heukelom J. The role of chloride transport in the control of the membrane potential in skeletal muscle--theory and experiment. Biophys Chem. 2009; 143:18-25. [PubMed: 19361905] 
Gellens ME, George AL Jr, Chen LQ, Chahine M, Horn R, Barchi RL, Kallen RG. Primary structure and functional expression of the human cardiac tetrodotoxin-insensitive voltage-dependent sodium channel. Proc. Nat. Acad. Sci. 1992; 89:554-558. [PubMed: 1309946]

George AL Jr, Komisarof J, Kallen RG, Barchi RL. Primary structure of the adult human skeletal muscle voltage-dependent sodium channel. Annals of Neurology. 1992; 31:131-137. [PubMed: 1315496]

Geukes Foppen RJ, van Mil HG, Siegenbeek van Heukelom J. Effects of chloride transport on bistable behaviour of the membrane potential in mouse skeletal muscle. J Physiol. 2002; 542:181-191. [PubMed: 12096060]

Gosselin-Badaroudine P, Delemotte L, Moreau A, Klein ML, Chahine M. Gating pore currents and the resting state of Nav1.4 voltage sensor domains. Proc Natl Acad Sci U S A. 2012; 109:1925019255. [PubMed: 23134726]

Green D, George A, Cannon S. Human sodium channel gating defects caused by missense mutations in S6 segments associated with myotonia: S804F and V1293I. J. Physiol. 1998; 510:685-694. [PubMed: 9660885]

Habbout K, Poulin H, Rivier F, Giuliano S, Sternberg D, Fontaine B, Eymard B, Morales RJ, Echenne B, King L, Hanna MG, Mannikko R, Chahine M, Nicole S, Bendahhou S. A recessive Nav1.4 mutation underlies congenital myasthenic syndrome with periodic paralysis. Neurology. 2016; 86:161-169. [PubMed: 26659129]

Hayward LJ, Brown RH Jr, Cannon SC. Inactivation defects caused by myotonia-associated mutations in the sodium channel III-IV linker. J. Gen. Physiol. 1996; 107:559-576. [PubMed: 8740371]

Hayward LJ, Brown RH Jr, Cannon SC. Slow inactivation differs among mutant Na channels associated with myotonia and periodic paralysis. Biophys. J. 1997; 72:1204-1219. [PubMed: 9138567]

Hayward LJ, Kim JS, Lee MY, Zhou H, Kim JW, Misra K, Salajegheh M, Wu FF, Matsuda C, Reid V, Cros D, Hoffman EP, Renaud JM, Cannon SC, Brown RH. Targeted mutation of mouse skeletal muscle sodium channel produces myotonia and potassium-sensitive weakness. J Clin Invest. 2008; 118:1437-1449. [PubMed: 18317596]

Hayward LJ, Sandoval GM, Cannon SC. Defective slow inactivation of sodium channels contributes to familial periodic paralysis. Neurology. 1999; 52:1447-1453. [PubMed: 10227633]

Heine R, Pika U, Lehmann-Horn F. A novel SCN4A mutation causing myotonia aggravated by cold and potassium. Human Molecular Genetics. 1993; 2:1349-1353. [PubMed: 8242056]

Horga A, Raja Rayan DL, Matthews E, Sud R, Fialho D, Durran SC, Burge JA, Portaro S, Davis MB, Haworth A, Hanna MG. Prevalence study of genetically defined skeletal muscle channelopathies in England. Neurology. 2013; 80:1472-1475. [PubMed: 23516313]

Huang W, Liu M, Yan SF, Yan N. Structure-based assessment of disease-related mutations in human voltage-gated sodium channels. Protein Cell. 2017; 8:401-438. [PubMed: 28150151]

Isom LL, De Jongh KS, Patton DE, Reber BF, Offord J, Charbonneau H, Walsh K, Goldin AL, Catterall WA. Primary structure and functional expression of the beta 1 subunit of the rat brain sodium channel. Science. 1992; 256:839-842. [PubMed: 1375395]

Jaimovich E, Venosa RA, Shrager P, Horowicz P. Density and distribution of tetrodotoxin receptors in normal and detubulated frog sartorius muscle. J Gen Physiol. 1976; 67:399-416. [PubMed: 1083895]

Jurkat-Rott K, Holzherr B, Fauler M, Lehmann-Horn F. Sodium channelopathies of skeletal muscle result from gain or loss of function. Pflugers Arch. 2010; 460:239-248. [PubMed: 20237798]

Jurkat-Rott K, Mitrovic N, Hang C, Kouzmekine A, Iaizzo P, Herzog J, Lerche H, Nicole S, ValeSantos J, Chauveau D, Fontaine B, Lehmann-Horn F. Voltage-sensor sodium channel mutations cause hypokalemic periodic paralysis type 2 by enhanced inactivation and reduced current. Proc Natl Acad Sci U S A. 2000; 97:9549-9554. [PubMed: 10944223]

Jurkat-Rott K, Weber MA, Fauler M, Guo XH, Holzherr BD, Paczulla A, Nordsborg N, Joechle W, Lehmann-Horn F. K+-dependent paradoxical membrane depolarization and $\mathrm{Na}$ + overload, major and reversible contributors to weakness by ion channel leaks. Proc Natl Acad Sci U S A. 2009; 106:4036-4041. [PubMed: 19225109] 
Kelly P, Yang WS, Costigan D, Farrell MA, Murphy S, Hardiman O. Paramyotonia congenita and hyperkalemic periodic paralysis associated with a Met 1592 Val substitution in the skeletal muscle sodium channel alpha subunit--a large kindred with a novel phenotype. Neuromuscular disorders : NMD. 1997; 7:105-111. [PubMed: 9131651]

Lehmann-Horn F, Jurkat-Rott K. Voltage-gated ion channels and hereditary disease. Physiol Rev. 1999; 79:1317-1372. [PubMed: 10508236]

Lehmann-Horn F, Kuther G, Ricker K, Grafe P, Ballanyi K, Rüdel R. Adynamia episodica hereditaria with myotonia: a non-inactivating sodium current and the effect of extracellular $\mathrm{pH}$. Muscle \& Nerve. 1987; 10:363-374. [PubMed: 3587272]

Lehmann-Horn, F., Rüdel, R., Jurkat-Rott, K. Nondystrophic myotonias and periodic paralyses. In: Engel, AG., Franzini-Armstrong, C., editors. Myology. McGraw-Hill; New York: 2004. p. 1257-1300.

Lerche H, Heine R, Pika U, George AL Jr, Mitrovic N, Browatzki M, Weiss T, Rivet-Bastide M, Franke C, Lomonaco M, Ricker K, Lehmann-Horn F. Human sodium channel myotonia: slowed channel inactivation due to substitutions for a glycine within the III-IV linker. J. Physiol. 1993; 470:13-22. [PubMed: 8308722]

Matthews E, Labrum R, Sweeney MG, Sud R, Haworth A, Chinnery PF, Meola G, Schorge S, Kullmann DM, Davis MB, Hanna MG. Voltage sensor charge loss accounts for most cases of hypokalemic periodic paralysis. Neurology. 2009; 72:1544-1547. [PubMed: 19118277]

Matthews E, Tan SV, Fialho D, Sweeney MG, Sud R, Haworth A, Stanley E, Cea G, Davis MB, Hanna MG. What causes paramyotonia in the United Kingdom? Common and new SCN4A mutations revealed. Neurology. 2008; 70:50-53. [PubMed: 18166706]

McClatchey AI, Cannon SC, Slaugenhaupt SA, Gusella JF. The cloning and expression of a sodium channel beta 1-subunit cDNA from human brain. Human Molecular Genetics. 1993; 2:745-749. [PubMed: 8394762]

McClatchey AI, McKenna-Yasek D, Cros D, Worthen HG, Kuncl RW, DeSilva SM, Cornblath DR, Gusella JF, Brown RH Jr. Novel mutations in families with unusual and variable disorders of the skeletal muscle sodium channel. Nature genetics. 1992; 2:148-152. [PubMed: 1338909]

Mi W, Rybalchenko V, Cannon SC. Disrupted coupling of gating charge displacement to Na+ current activation for DIIS4 mutations in hypokalemic periodic paralysis. The Journal of general physiology. 2014; 144:137-145. [PubMed: 25024265]

Miller TM, Dias da Silva MR, Miller HA, Kwiecinski H, Mendell JR, Tawil R, McManis P, Griggs RC, Angelini C, Servidei S, Petajan J, Dalakas MC, Ranum LP, Fu YH, Ptacek LJ. Correlating phenotype and genotype in the periodic paralyses. Neurology. 2004; 63:1647-1655. [PubMed: 15534250]

Mitrovic N, George AL Jr, Lerche H, Wagner S, Fahlke C, Lehmann-Horn F. Different effects on gating of three myotonia-causing mutations in the inactivation gate of the human muscle sodium channel. J. Physiol. 1995; 487:107-114. [PubMed: 7473241]

Moreau A, Gosselin-Badaroudine P, Chahine M. Molecular biology and biophysical properties of ion channel gating pores. Q Rev Biophys. 2014; 47:364-388. [PubMed: 25382261]

Palade PT, Barchi RL. Characteristics of the chloride conductance in muscle fibers of the rat diaphragm. J. Gen. Physiol. 1977; 69:325-342. [PubMed: 15046]

Rogart RB, Regan LJ. Two types of sodium channel with tetrodotoxin sensitivity and insensitivity detected in denervated mammalian skeletal muscle. Brain Res. 1985; 329:314-318. [PubMed: 2579711]

Rüdel R, Lehmann-Horn F. Membrane changes in cells from myotonia patients. Physiol. Rev. 1985; 65:310-356. [PubMed: 2580324]

Rüdel R, Ricker K, Lehmann-Horn F. Genotype-phenotype correlations in human skeletal muscle sodium channel diseases. Arch. Neurol. 1993; 50:1241-1248. [PubMed: 8215982]

Rudolph JA, Spier SJ, Byrns G, Rojas CV, Bernoco D, Hoffman EP. Periodic paralysis in quarter horses: a sodium channel mutation disseminated by selective breeding. Nature Genetics. 1992; 2:144-147. [PubMed: 1338908]

Ruff RL. Slow Na+ channel inactivation must be disrupted to evoke prolonged depolarization-induced paralysis. Biophys. J. 1994; 66:542-545. [PubMed: 8161707] 
Ruff RL. Insulin acts in hypokalemic periodic paralysis by reducing inward rectifier $\mathrm{K}+$ current. Neurology. 1999; 53:1556-1563. [PubMed: 10534267]

Siegenbeek van Heukelom J. Role of the anomalous rectifier in determining membrane potentials of mouse muscle fibres at low extracellular K+ J Physiol. 1991; 434:549-560. [PubMed: 2023129]

Simoncini L, Stuhmer W. Slow sodium channel inactivation in rat fast-twitch muscle. J. Physiol. 1987; 383:327-337. [PubMed: 2443649]

Singh RR, Tan SV, Hanna MG, Robb SA, Clarke A, Jungbluth H. Mutations in SCN4A: a rare but treatable cause of recurrent life-threatening laryngospasm. Pediatrics. 2014; 134:e1447-1450. [PubMed: 25311598]

Sokolov S, Scheuer T, Catterall WA. Ion permeation through a voltage- sensitive gating pore in brain sodium channels having voltage sensor mutations. Neuron. 2005; 47:183-189. [PubMed: 16039561]

Sokolov S, Scheuer T, Catterall WA. Gating pore current in an inherited ion channelopathy. Nature. 2007; 446:76-78. [PubMed: 17330043]

Starace DM, Bezanilla F. Histidine scanning mutagenesis of basic residues of the S4 segment of the shaker k+ channel. J Gen Physiol. 2001; 117:469-490. [PubMed: 11331357]

Starace DM, Bezanilla F. A proton pore in a potassium channel voltage sensor reveals a focused electric field. Nature. 2004; 427:548-553. [PubMed: 14765197]

Starace DM, Stefani E, Bezanilla F. Voltage-dependent proton transport by the voltage sensor of the Shaker K+ channel. Neuron. 1997; 19:1319-1327. [PubMed: 9427254]

Sternberg D, Maisonobe T, Jurkat-Rott K, Nicole S, Launay E, Chauveau D, Tabti N, Lehmann-Horn F, Hainque B, Fontaine B. Hypokalaemic periodic paralysis type 2 caused by mutations at codon 672 in the muscle sodium channel gene SCN4A. Brain. 2001; 124:1091-1099. [PubMed: 11353725]

Struyk AF, Cannon SC. A Na ${ }^{+}$Channel Mutation Linked to Hypokalemic Periodic Paralysis Exposes a Proton-selective Gating Pore. J Gen Physiol. 2007; 130:11-20. [PubMed: 17591984]

Struyk AF, Cannon SC. Paradoxical depolarization of $\mathrm{Ba}^{2+}$ - treated muscle exposed to low extracellular $\mathrm{K}+$ : insights into resting potential abnormalities in hypokalemic paralysis. Muscle Nerve. 2008; 37:326-337. [PubMed: 18041053]

Struyk AF, Markin VS, Francis D, Cannon SC. Gating pore currents in DIIS4 mutations of NaV1.4 associated with periodic paralysis: saturation of ion flux and implications for disease pathogenesis. J Gen Physiol. 2008; 132:447-464. [PubMed: 18824591]

Struyk AF, Scoggan KA, Bulman DE, Cannon SC. The human skeletal muscle Na channel mutation R669H associated with hypokalemic periodic paralysis enhances slow inactivation. J Neurosci. 2000; 20:8610-8617. [PubMed: 11102465]

Stühmer W, Conti F, Suzuki H, Wang XD, Noda M, Yahagi N, Kubo H, Numa S. Structural parts involved in activation and inactivation of the sodium channel. Nature. 1989; 339:597-603. [PubMed: 2543931]

Tao X, Lee A, Limapichat W, Dougherty DA, MacKinnon R. A gating charge transfer center in voltage sensors. Science. 2010; 328:67-73. [PubMed: 20360102]

Tombola F, Pathak MM, Isacoff EY. Voltage-sensing arginines in a potassium channel permeate and occlude cation-selective pores. Neuron. 2005; 45:379-388. [PubMed: 15694325]

Trimmer JS, Cooperman SS, Tomiko SA, Zhou J, Crean SM, Boyle MB, Kallen RG, Sheng Z, Barchi RL, Sigworth FJ, Goodman RH, Agnew WS, Mandel G. Primary structure and functional expression of a mammalian skeletal muscle sodium channel. Neuron. 1989; 3:33-49. [PubMed: 2559760]

Tsujino A, Maertens C, Ohno K, Shen XM, Fukuda T, Harper CM, Cannon SC, Engel AG. Myasthenic syndrome caused by mutation of the SCN4A sodium channel. Proc Natl Acad Sci U S A. 2003; 100:7377-7382. [PubMed: 12766226]

Wang J, Zhou J, Todorovic SM, Feero WG, Barany F, Conwit R, Hausmanowa-Petrusewicz I, Fidzianska A, Arahata K, Wessel HB, Sillen A, Marks HG, Hartlage P, Galloway G, Ricker K, Lehmann-Horn F, Hayakawa H, Hoffman EP. Molecular genetic and genetic correlations in sodium channelopathies: lack of founder effect and evidence for a second gene. Am. J. Hum. Genet. 1993; 52:1074-1084. [PubMed: 8389097] 
West JW, Patton DE, Scheuer T, Wang Y, Goldin AL, Catterall WA. A cluster of hydrophobic amino acid residues required for fast $\mathrm{Na}^{+}$-channel inactivation. Proc. Nat. Acad. Sci. 1992; 89:1091010914. [PubMed: 1332060]

Wood ML, Freites JA, Tombola F, Tobias DJ. Atomistic Modeling of Ion Conduction through the Voltage-Sensing Domain of the Shaker K+ Ion Channel. J Phys Chem B. 2017; 121:3804-3812. [PubMed: 28074656]

Wu F, Mi W, Burns DK, Fu Y, Gray HF, Struyk AF, Cannon SC. A sodium channel knockin mutant (NaV1.4-R669H) mouse model of hypokalemic periodic paralysis. J Clin Invest. 2011; 121:40824094. [PubMed: 21881211]

Wu F, Mi W, Cannon SC. Bumetanide prevents transient decreases in muscle force in murine hypokalemic periodic paralysis. Neurology. 2013; 80:1110-1116. [PubMed: 23427324]

Wu F, Mi W, Fu Y, Struyk A, Cannon SC. Mice with an NaV1.4 sodium channel null allele have latent myasthenia, without susceptibility to periodic paralysis. Brain. 2016; 139:1688-1699. [PubMed: 27048647]

Wu F, Mi W, Hernandez-Ochoa EO, Burns DK, Fu Y, Gray HF, Struyk AF, Schneider MF, Cannon SC. A calcium channel mutant mouse model of hypokalemic periodic paralysis. J Clin Invest. 2012; 122:4580-4591. [PubMed: 23187123]

Wu FF, Gordon E, Hoffman EP, Cannon SC. A C-terminal skeletal muscle sodium channel mutation associated with myotonia disrupts fast inactivation. J Physiol. 2005; 565:371-380. [PubMed: 15774523]

Yang JS, Sladky JT, Kallen RG, Barchi RL. TTX-sensitive and TTX-insensitive sodium channel mRNA transcripts are independently regulated in adult skeletal muscle after denervation. Neuron. 1991; 7:421-427. [PubMed: 1654949]

Yang N, Ji S, Zhou M, Ptacek LJ, Barchi RL, Horn R, George AL Jr. Sodium channel mutations in paramyotonia congenita exhibit similar biophysical phenotypes in vitro. Proc. Nat. Acad. Sci. 1994; 91:12785-12789. [PubMed: 7809121]

Zaharieva I, Thor M, Oates E, Karnebeek C, Hendson G, Blom E, Witting N, Rasmussen M, Gabbett M, Ravenscroft G, Sframeli M, Sutterlin K, Sarkozy A, D'Argenzio, Hartley L, Matthews E, Pitt M, Vissing J, Bellegaard M, Krarup C, Slordhal A, Halvorson H, Ye C, Zhang LH, Lokken N, Werlauf U, Abdelsayed M, Davis MR, Feng L, Phadke R, Sewry CA, Morgan JE, Laing NG, Vallance H, Ruben P, Hanna MG, Lewis S, Kamsteeg EJ, Mannikko R, Mutoni F. Recessive lossof-function SCN4A mutations associated with a novel phenotype of congenital myopathy. Brain. 2015

Handb Exp Pharmacol. Author manuscript; available in PMC 2018 June 06. 


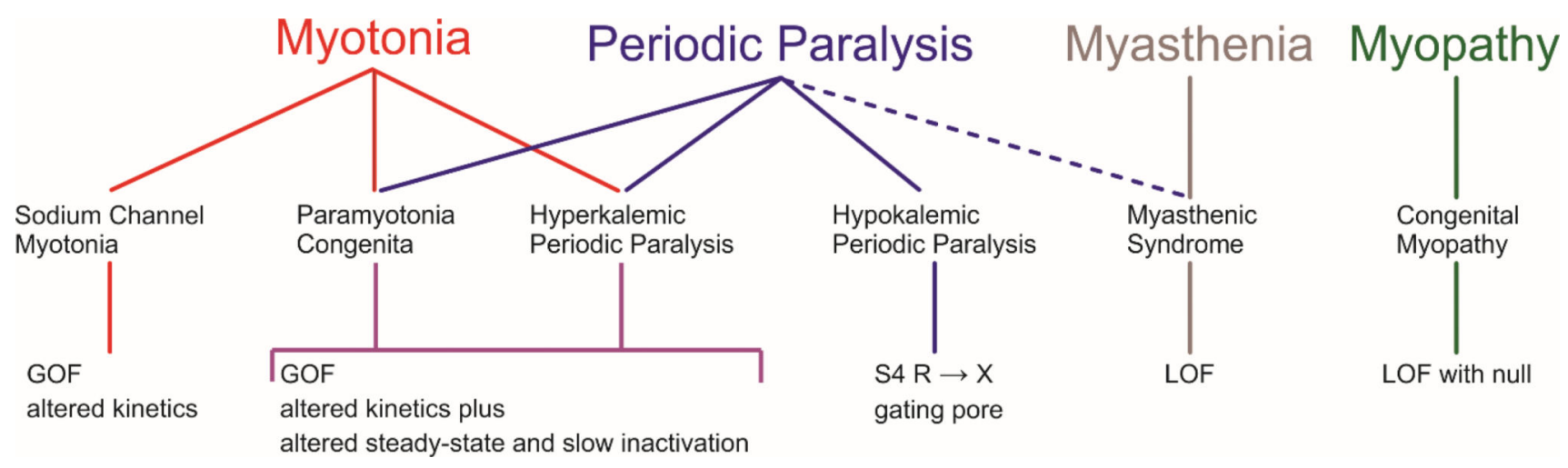

Figure XX.1.

Spectrum of clinical phenotypes, muscle diseases, and functional deficits for $\mathrm{Na}_{\mathrm{V}} 1.4$ channelopathies. Paramyotonia congenita and hyperkalemic periodic paralysis have considerable overlap in clinical features and $\mathrm{Na}_{\mathrm{V}} 1.4$ deficits. Sustained fluctuations in muscle strength may occur with myasthenia (dashed line), but the relation to periodic paralysis is uncertain. Abbreviations: GOF gain-of-function, LOF loss-of-function. 
a
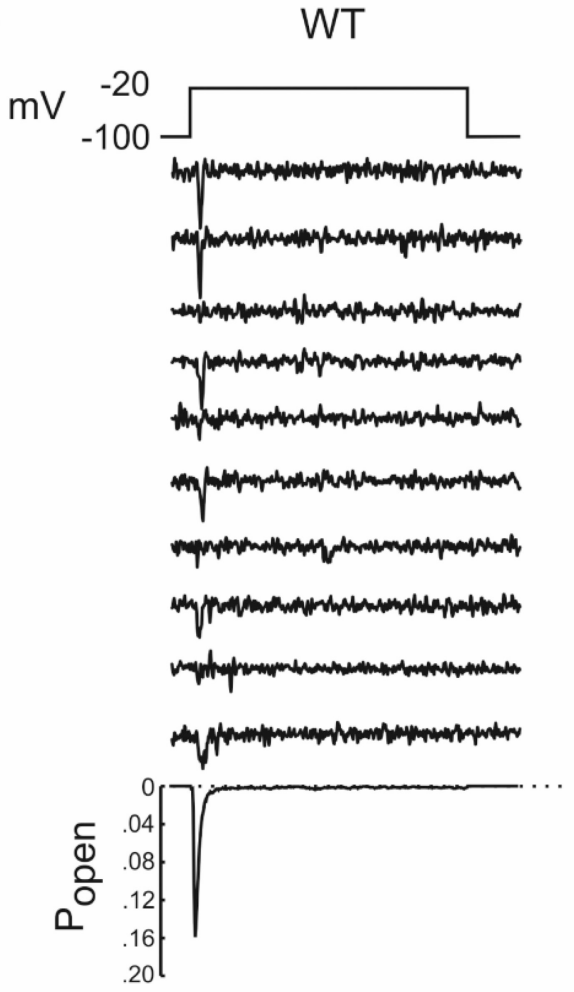

b

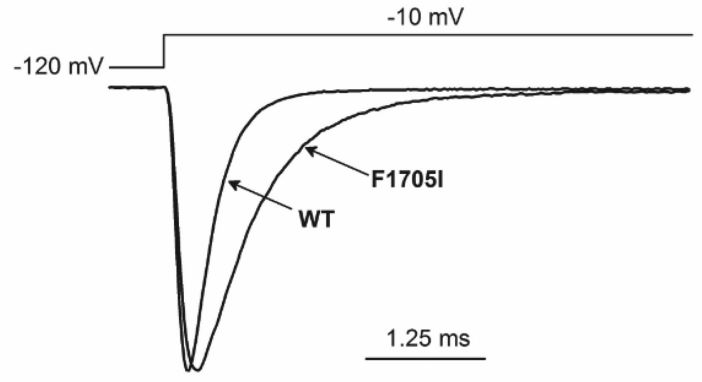

T704M
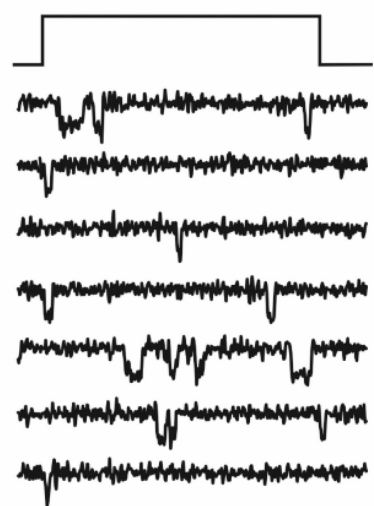

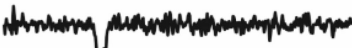

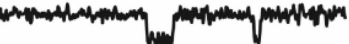

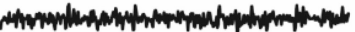

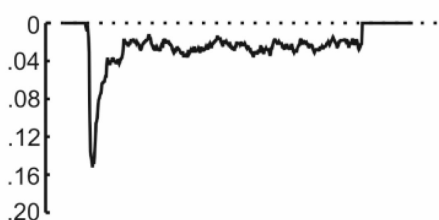

C

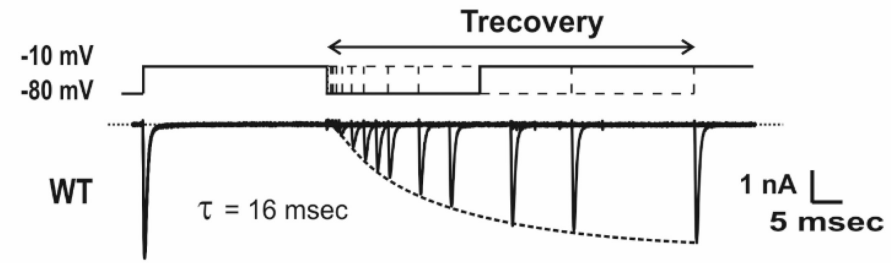

$\mathrm{T} 1313 \mathrm{M}$

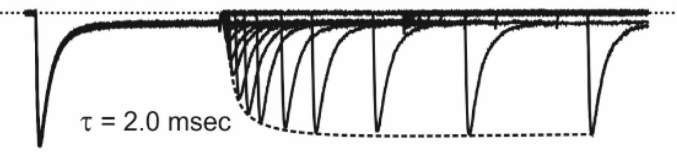

Figure XX.2.

Impairment of fast inactivation for $\mathrm{Na}_{\mathrm{V}} 1.4$ mutations found in myotonia and HyperPP. (a) Cell-attached patch recordings from HEK cells show channel re-openings and prolonged open events for the two most commonly occurring HyperPP mutations (T704M and M1592V). Ensemble average (bottom) shows a small non-inactivating component (adapted from (Cannon and Strittmatter, 1993)) (b) Amplitude normalized whole-cell current shows a slower rate of inactivation for the SCM mutation F1705I (adapted from (Wu et al., 2005)). (c) Accelerated rate of recovery from fast inactivation for the PMC mutation T1313M (adapted from (Hayward et al., 1996)). 

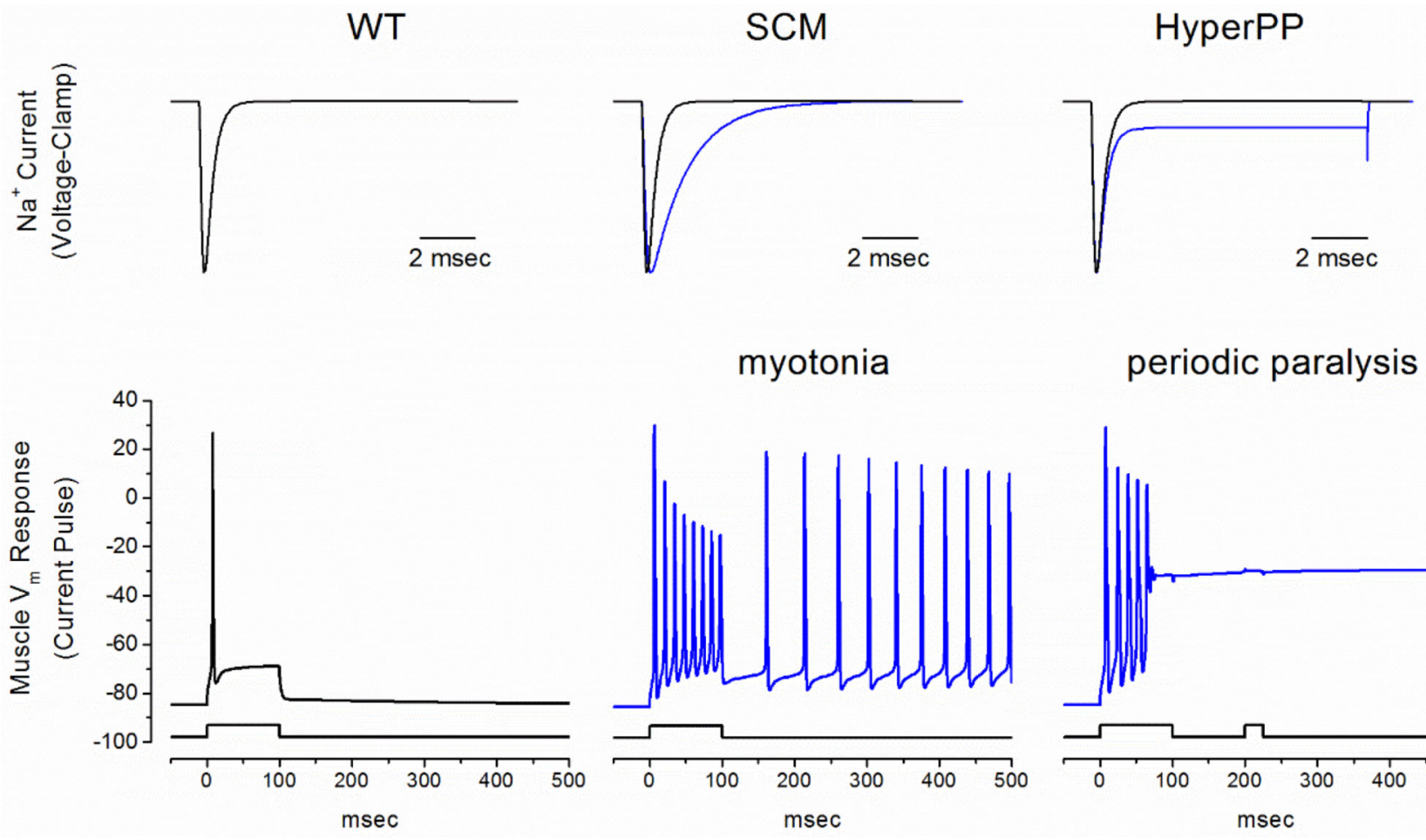

periodic paralysis

Figure XX.3.

Model simulation of myotonia and periodic paralysis resulting from gain-of-function defects in $\mathrm{Na}_{V}$ 1.4. Top row shows simulated $\mathrm{Na}_{\mathrm{V}} 1.4$ mutant currents (blue lines) typical for SCM (middle) and HyperPP (right). A two-compartment model for skeletal muscle (Cannon et al., 1993a), to simulate the sarcolemma and the t-tubule including $\mathrm{K}^{+}$accumulation, was used to simulate the response to simulated current injection. The simulated muscle normally fires a single action potential and then accommodates (left, note the difference in time scale compared to the top row). A reduced rate for onset of fast inactivation as in SCM (middle) gives rise to a sustained burst of myotonic discharges that persists after termination of the stimulus. A small persistent $\mathrm{Na}^{+}$current to simulate HyperPP (right) also results in an initial myotonic burst, but then the membrane potential settles on an anomalously depolarized value, which inactivates the majority of $\mathrm{Na}_{\mathrm{V}} 1.4$ channels and renders the fiber refractory from a second stimulus pulse. 
a

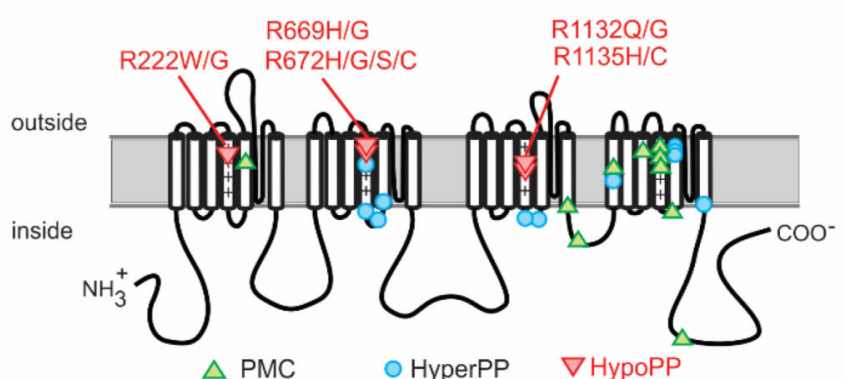

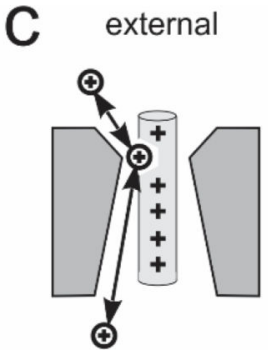

Internal external

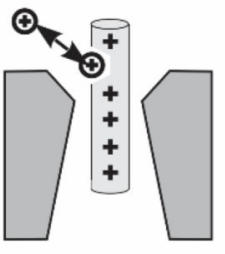

Internal

b
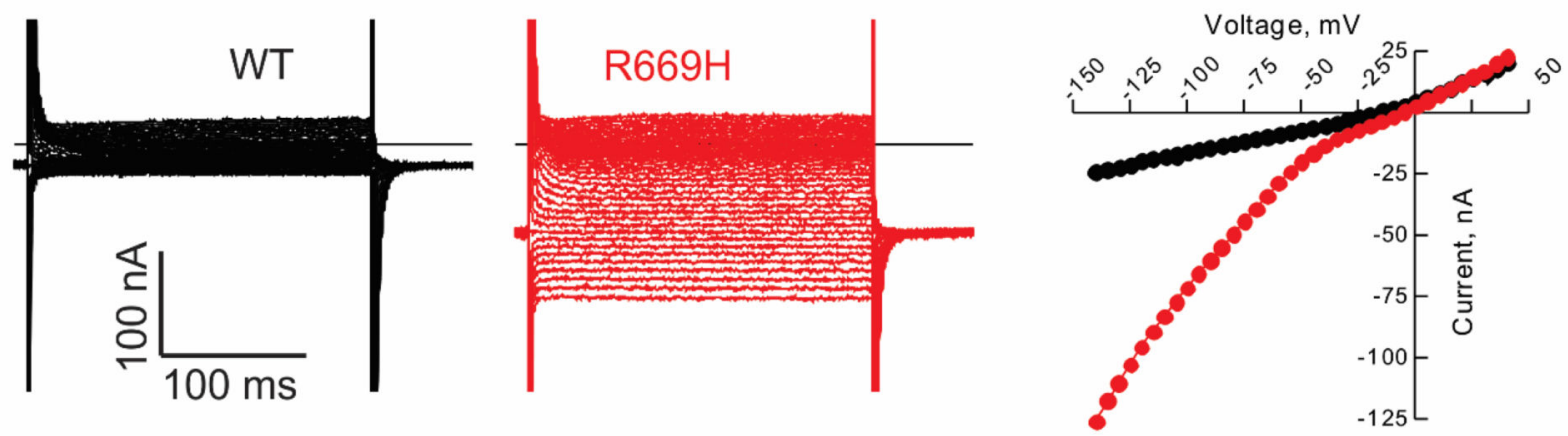

Figure XX.4.

Gating pore currents in Nav1.4 HypoPP mutant channels. (a) Schematic representation of the $\mathrm{Na}_{V} 1.4$ a subunit showing the location of missense mutations associated with muscle syndromes that include periodic paralysis (PMC, HyperPP, HypoPP). The HypoPP mutations are all at arginine residences in S4 segments and none are in domain IV. (b) Currents recorded from oocytes expressing wild type (WT, black) or R669H HypoPP mutant channels (red) in the presence of $1 \mu \mathrm{M}$ TTX to block the Nav1.4 pore. The steady-state I-V relation shows inward rectification for $\mathrm{R} 669 \mathrm{H}$ but not WT channels. (C) Inward rectification is consistent with a gating pore current resulting from a voltage-dependent anomalous conduction pathway that allows cation permeation only when the mutant residue of S4 is within the gating charge transfer center. 


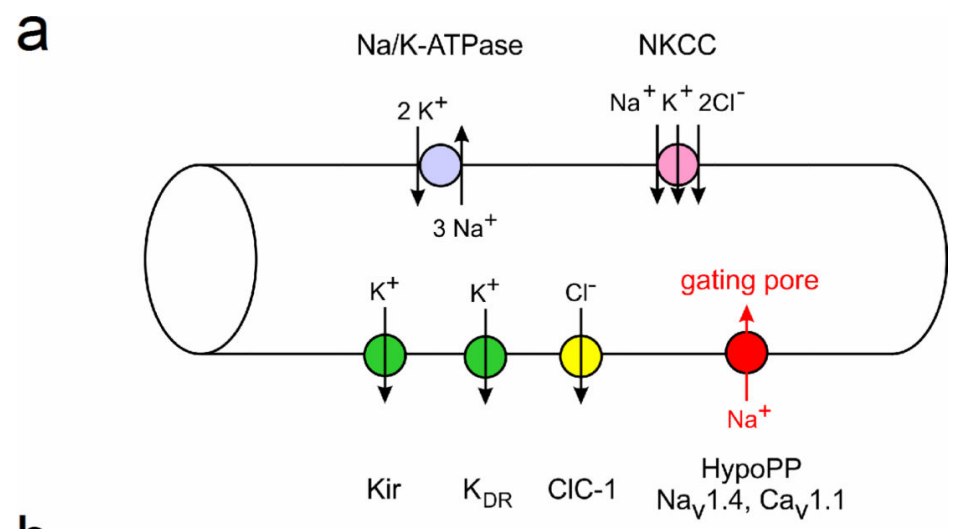

b
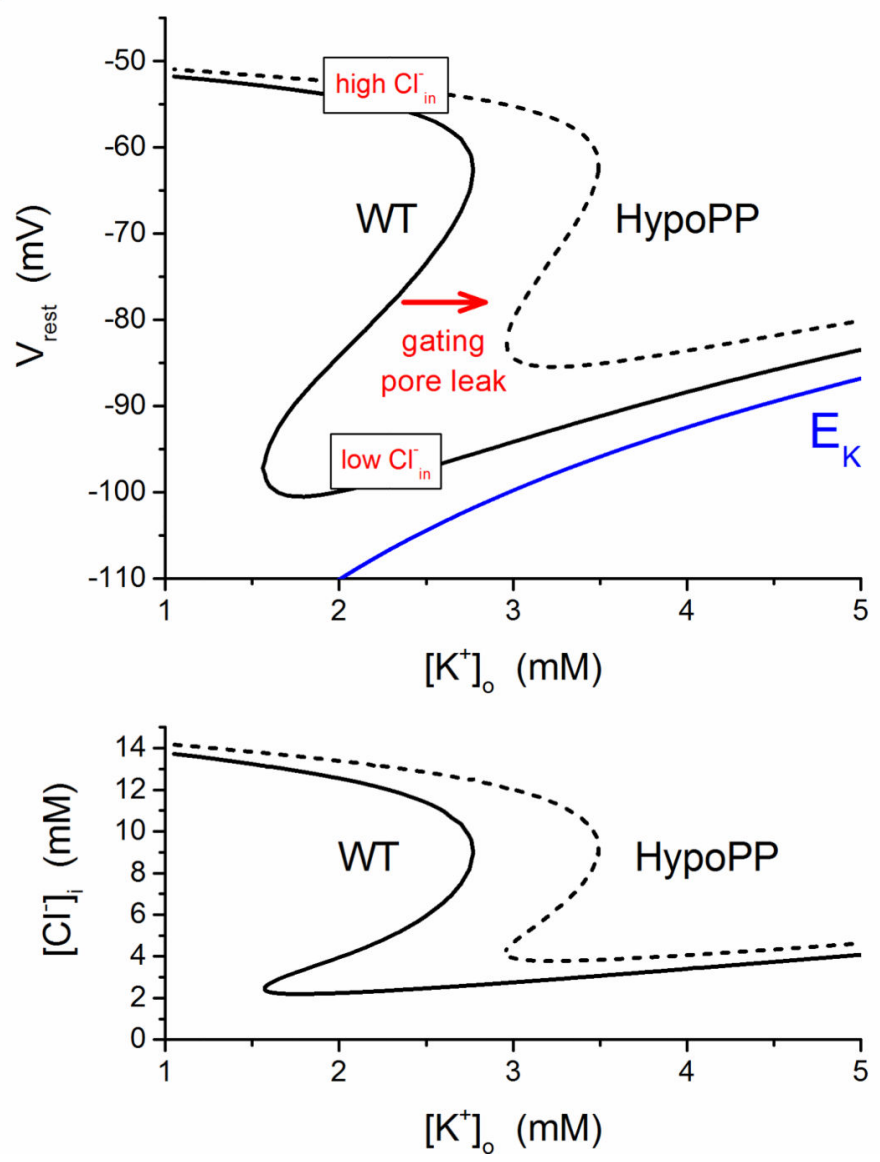

Figure XX.5.

Simulated paradoxical depolarization in low $\mathrm{K}^{+}$for a model HypoPP fiber. (a) Diagram of the pumps and transporters (top side) and ion channels (bottom side) to simulate the dependence of $\mathrm{V}_{\text {rest }}$ on extracellular $\mathrm{K}^{+}$. Arrows indicate the direction of net transport for specific ions when the fiber is at the normal $\mathrm{V}_{\text {rest }}$. The gating pore is present in HypoPP fibers only, has a reversal potential near $0 \mathrm{mV}$, and in this simulation is carried primarily $\mathrm{Na}^{+}$ influx. (b) Phase plot of $\mathrm{V}_{\text {rest }}$ (top) and intracellular $\mathrm{Cl}^{-}$(bottom) as the extracellular $\mathrm{K}^{+}$was varied from 1 to $5 \mathrm{mM}$. At each set value of $\mathrm{K}^{+}$, the simulation searched for values of the membrane potential and internal $\mathrm{Cl}^{-}$that simultaneously satisfied two constraints: that the 
sum of all ionic currents was zero (equilibrium point for $\mathrm{Vm}$ ) and that the net $\mathrm{Cl}^{-}$flux was also zero (mass balance for NKCC influx and ClC-1 efflux). For comparison, the Nernst potential for $\mathrm{K}^{+}$is shown in blue. For a simulated WT fiber (solid line), $\mathrm{V}_{\text {rest }}$ hyperpolarizes as $\mathrm{K}^{+}$is lowered from $5 \mathrm{mM}$ until about $1.5 \mathrm{mM}$, at which point the fiber paradoxically depolarizes to $-52 \mathrm{mV}$. This transition occurs because in very low $\mathrm{K}^{+}$the Kir conductance can no longer balance the inward $\mathrm{Cl}^{-}$current. The fiber depolarizes, which must be accompanied with an increase of intracellular $\mathrm{Cl}^{-}$(bottom) because of the high resting $\mathrm{Cl}^{-}$ conductance. Addition of the gating pore current in a simulated HypoPP fiber (dashed line), shifts the relation to the right such that the paradoxical depolarization now occurs at $3 \mathrm{mM}$ which is in the low physiologic range. The system has the possibility of multiple equilibrium potentials at a single value of external $\mathrm{K}^{+}$. For example, in the WT fiber this region of bistability for $\mathrm{V}_{\text {rest }}$ was with $\mathrm{K}^{+}$between 1.5 and $2.75 \mathrm{mM}$. The internal $\left[\mathrm{Cl}^{-}\right]$determines which value of $\mathrm{V}_{\text {rest }}$ will the fiber will settle upon (hyperpolarized for low $\mathrm{Cl}^{-}$and depolarized for high $\mathrm{Cl}^{-}$). 
WT / WT

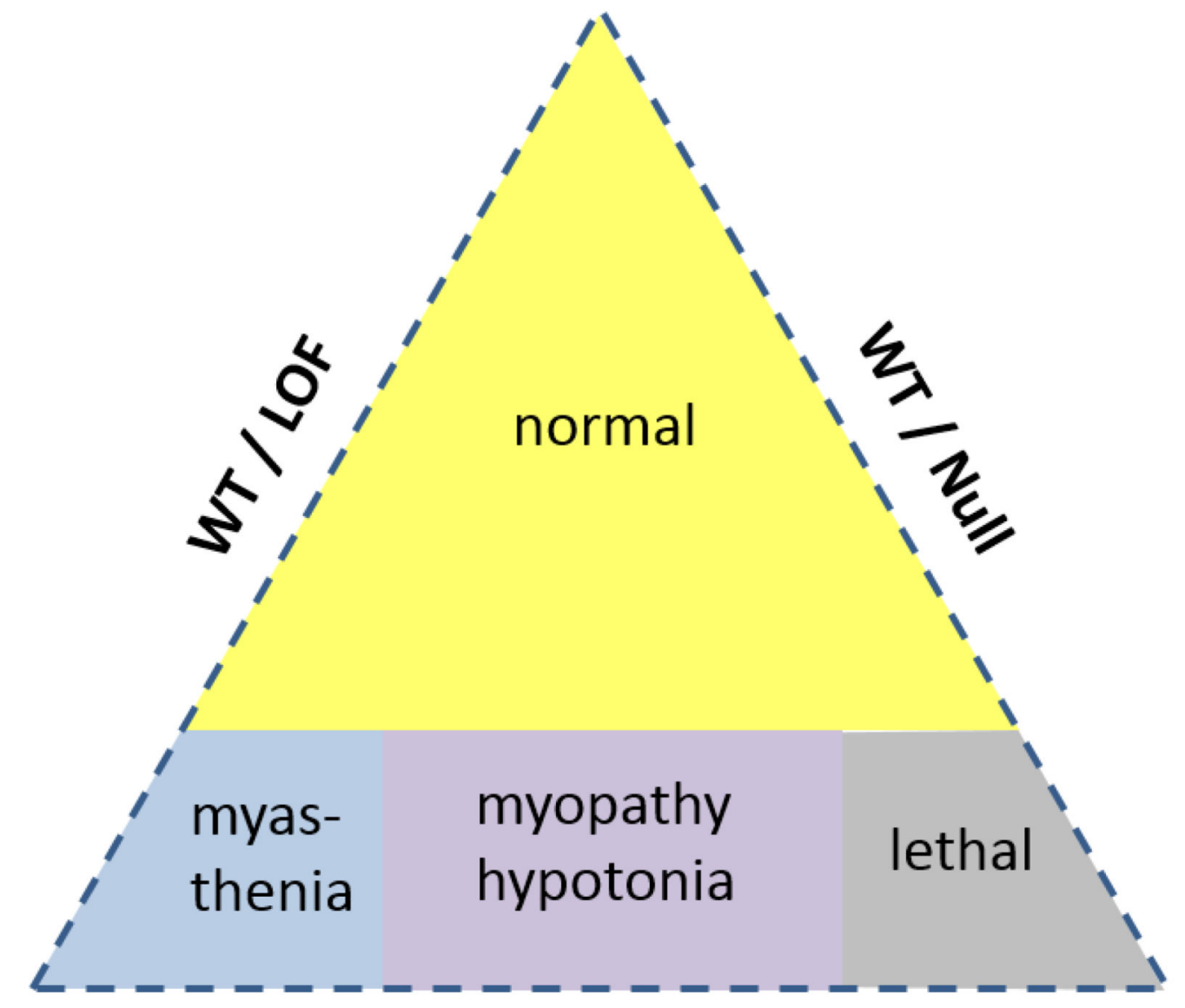

LOF / LOF

LOF / Null

Null / Null

Figure XX.6.

Diagram illustrating the relationship between wild-type (WT), loss-of-function (loss), and null alleles for $\mathrm{Na}_{\mathrm{V}} 1.4$ in determining the clinical phenotype. The loss-of-function refers to mutant $\mathrm{Na}$ 1.4 channels that express and conduct $\mathrm{Na}^{+}$current, albeit with reduced amplitude or duration, as distinct from the complete absence of function with a null allele. (Reproduced from (Cannon, 2016)). 